\title{
Activation of CPP32-like Protease in Tumor Necrosis Factor-induced Apoptosis is Dependent on Mitochondrial Function
}

\author{
Masahiro Higuchi, ${ }^{\star}$ Bharat B. Aggarwal, ${ }^{\S}$ and Edward T.H.Yeh ${ }^{\star \ddagger}$ \\ ${ }^{*}$ Research Center for Cardiovascular Diseases, Institute of Molecular Medicine for the Prevention of Human Diseases; ${ }^{\ddagger}$ Division of \\ Molecular Medicine, Department of Internal Medicine, The University of Texas-Houston Health Science Center, Houston, Texas 77030; \\ and ${ }^{\S}$ Cytokine Research Laboratory, Department of Molecular Oncology, The University of Texas, M.D. Anderson Cancer Center, \\ Houston, Texas 77030
}

\begin{abstract}
Mitochondria have been implicated in apoptosis, however, the precise mechanisms whereby mitochondria exert their effect are not clear. To gain further insights, we generated a panel of cells from ML-1a cells that were rendered respiration deficient by ethidium bromide treatment. Two respiration-deficient clones were subsequently reconstituted by fusion with platelets. Respiration-deficient clones were resistant to TNF-induced apoptosis, whereas ML-1a and reconstituted clones were sensitive. In contrast, inhibition of proliferation and induction of differentiation by TNF were still observed in respiration deficient clones, suggesting a selective requirement of respiration in TNF-induced apoptosis. Furthermore the apoptosis machinery is not completely altered in respiration-deficient cells because they underwent apoptosis after staurosporine treatment. Next, we showed that apoptosis induced by TNF and staurosporine were blocked by z-DEVD- $\mathrm{CH}_{2} \mathrm{~F}$, an inhibitor of CPP32-like cysteine protease, suggesting the involvement of CPP32-like protease in both apoptosis signaling pathways. Interestingly, TNF activated CPP32-like protease in the parental and reconstituted clones but not in respiration-deficient clones, and staurosporine in all clones. Thus, the apoptosis signaling block in respiration-deficient clones is located at a step before CPP32-like protease activation, which can be bypassed by staurosporine. (J. Clin. Invest. 1997. 99:17511758.) Key words: tumor necrosis factor - mitochondria • CPP32 • staurosporine $\bullet$ apoptosis
\end{abstract}

\section{Introduction}

Tumor necrosis factor was first described from the sera of rodents and characterized as a monokine that induces necrosis of certain tumors in vivo (1). It is cytotoxic toward a wide range of tumor cell lines in vitro, but the exact mechanisms underlying the cytotoxic activity of TNF are not fully understood.

Several signaling mediators including oxygen radicals (2-5), phospholipase $A_{2}(6-8)$, ceramide $(9,10)$, and proteases (11-14) have been demonstrated in TNF-induced cytotoxicity.

Address correspondence to Masahiro Higuchi, Institute of Molecular Medicine for the Prevention of Human Diseases, $2121 \mathrm{~W}$. Holcombe, Houston, TX 77030. Phone: 713-500-2429; FAX: 713-500-2424; E-mail: masahiro.higuchi@uth.tmc.edu

Received for publication 5 November 1996 and accepted in revised form 10 January 1997.

J. Clin. Invest.

(c) The American Society for Clinical Investigation, Inc.

0021-9738/97/04/1751/08 \$2.00

Volume 99, Number 7, April 1997, 1751-1758
Because introduction of proteases such as trypsin, chymotrypsin, and proteinase $\mathrm{K}$ into the cells can induce apoptosis (15), the activation of certain proteases may be a key step in apoptosis induction. Recently, CPP32, a member of ICE family cysteine proteases, has emerged as one of the key proteases in spontaneous (16), anti-Fas- (17) and staurosporine-mediated apoptosis (18). Although TNF can activate CPP32-like protease (19), and overexpression of crm A that inhibit ICE family cysteine protease can inhibit TNF-induced cell death (14), the involvement of CPP32 in TNF-induced apoptosis has not been formerly demonstrated. FLICE/MACH, another member of the ICE member cysteine proteases, was shown to be recruited to form a complex with Fas and FADD/MORT1 $(20,21)$. Since overexpression of the dominant negative FLICE/MACH inhibited Fas-mediated and TNF-mediated apoptosis (21), the activation of FLICE/MACH may be another key step for Fas- and TNF-induced apoptosis. Although several mediators mentioned above are involved in TNFinduced cytotoxicity, the precise activation mechanisms, their ordering in cell death pathway, and their interdependence are incompletely understood.

Mitochondria have been implicated in TNF-induced cell death. After TNF treatment, mitochondria swell (2) and mitochondrial respiration chains $(\mathrm{MRC})^{1}$ are damaged $(3,4)$ in the early phase of cell death. Because mitochondria are the source of ATP, damage to mitochondria will ultimately decrease cellular ATP levels leading to cell death. In addition to the passive cytotoxic effect of decreasing ATP level, additional mechanisms may be directly involved in TNF-induced cytotoxicity. Since mitochondria are a main source of reactive oxygen species (ROS), which has been implicated in both apoptosis and necrosis (22), mitochondria-derived ROS may provide a link between mitochondria and cell death. This hypothesis is also supported by the observation that manganese superoxide dismutase, which inactivates mitochondrial $\mathrm{O}_{2}{ }^{-}$that has leaked from the electron transport chain, abrogates TNF-mediated apoptosis (23). Furthermore, TNF-induced ROS production in the mitochondria $(24,25)$ and damage to the MRC by ROS induced by TNF (4) have also been reported. Another possible mechanism by which mitochondria could play a direct role in cell death includes the release of $\mathrm{Ca}^{2+}$ (26). In addition, Zamzami et al. (27) reported that mitochondrial permeability transition is a critical step of the apoptotic cascade. Furthermore, overexpression of Bcl-2 abrogated TNF-induced apoptosis and increased mitochondrial membrane potential, suggesting that mitochondria play a critical role in apoptosis (28). Recently Liu et al. (29) shows that cytochrome $c$ release from mitochondria is a key step in staurosporine-mediated apopto-

1. Abbreviations used in this paper: MRC, mitochondrial respiration chain; ROS, reactive oxygen species. 
sis, suggesting that damage to mitochondria can induce apoptosis. Because most of the studies of TNF-induced cytotoxicity cited above were performed in L929 cells, where TNF induces necrosis $(30,31)$, the role of mitochondria in TNF-induced apoptosis remains unclear.

To investigate the requirement of mitochondrial function in TNF-induced apoptosis signaling, we generated a panel of respiration-deficient clones and their reconstituted cybrids. We show that mitochondrial respiratory activity is highly correlated with the ability of TNF to induce apoptosis. In addition, we showed that functional mitochondria is necessary for TNF-, but not staurosporine-induced activation of CPP32. Our study thus placed mitochondria in a step before the activation of a CPP32-like protease in TNF-induced apoptosis signaling.

\section{Methods}

Materials. RPMI-1640 medium, gentamicin, and FCS were obtained from GIBCO (Grand Island, NY), phenylmethanesulfonyl fluoride, leupeptin, aprotinin, pepstatin, staurosporine, okadaic acid, glycerol, dithiothreitol, EGTA, EDTA, uridine, glucose, pyruvate, polyethylene glycol 2000, Triton X-100, dimethyl sulfoxide, phorbol myristic acetate, nitroblue tetrazolium, digitonin, ADP, succinate, sucrose, Hepes, and H-7 were obtained from Sigma Chemical Co. (St. Louis, MO). z-DEVD $\mathrm{CH}_{2} \mathrm{~F}$ and acetyl-Asp-Glu-Val-Asp-aminomethylcoumarin were from Calbiochem Corp. (La Jolla, CA). Bacteria-derived recombinant human TNF, purified to homogeneity with a specific activity of $5 \times 10^{7} \mathrm{U} / \mathrm{mg}$, was kindly provided by Genentech Inc., South San Francisco, CA.

Cell lines. Myelogenous leukemia ML-1a cells were obtained from Dr. Ken Takeda (Showa University, Tokyo, Japan). All cell lines except clones 2, 5, 11, 19, and 20 were grown in RPMI-1640 medium supplemented with $10 \%$ FCS and gentamicin $(50 \mu \mathrm{g} / \mathrm{ml})$ (essential medium). Clones 2, 5, 11, 19, and 20 were grown in RPMI-1640 medium with $10 \%$ FCS and gentamicin $(50 \mu \mathrm{g} / \mathrm{ml})$ supplemented with $4.5 \mathrm{mg} / \mathrm{ml}$ glucose, $50 \mu \mathrm{g} / \mathrm{ml}$ uridine, and $100 \mu \mathrm{g} / \mathrm{ml}$ pyruvate (enriched medium). The cells were seeded at a density of $1 \times 10^{5}$ cells $/ \mathrm{ml}$ in T-25 flasks (Falcon 3013; Becton Dickinson Labware, Lincoln Park, NJ) containing $10 \mathrm{ml}$ of medium and grown at $37^{\circ} \mathrm{C}$ in an atmosphere of $95 \%$ air and $5 \% \mathrm{CO}_{2}$. Cell cultures were split every 3-5 d.

Establishment of respiration-deficient and free cells. ML-1a cells were incubated in enriched medium in the presence of $200 \mathrm{ng} / \mathrm{ml}$ ethidium bromide for $8 \mathrm{wk}$ to select respiration-deficient cells. Subcloning was done by limiting dilution. Five clones, clones 2, 5, 11, 19, and 20, grew well in enriched medium but did not survive in essential medium. Respiration-deficient cells have been reported to become pyrimidine auxotrophs, suggesting that respiration is defective in these clones (32).

Fusion of clone 19 and clone 20 with platelets. Fusion of platelets with respiration-deficient and free cells was performed by a slightly modified variation of the method of Chomyn et al. (33). Briefly, heparinized whole blood was centrifuged for $15 \mathrm{~min}$ at $150 \mathrm{~g}$ at $4^{\circ} \mathrm{C}$, and platelet-rich plasma recovered. Phosphate-buffered saline was added, and the mixture centrifuged for $15 \mathrm{~min}$ at $150 \mathrm{~g}$ at $4^{\circ} \mathrm{C}$. The platelet fraction, no other cell type but platelets, was obtained and centrifuged for $30 \mathrm{~min}$ at $2,000 \mathrm{~g}$ at $4^{\circ} \mathrm{C}$. The pellet was then suspended in phosphate-buffered saline. $1 \times 10^{7}$ platelets and $2 \times 10^{5}$ clone 19 or clone 20 cells were mixed in PBS and centrifuged at $160 \mathrm{~g}$ for $10 \mathrm{~min}$. The supernatant was aspirated, and a polyethylene glycol solution (45\% of polyethylene glycol 2000 in Hanks balanced solution) was added. After a 1-min incubation at $37^{\circ} \mathrm{C}, 9 \mathrm{ml}$ of RPMI-1640 medium was added slowly. The cells were then centrifuged for $5 \mathrm{~min}$ at $150 \mathrm{~g}$, suspended in $2 \mathrm{ml}$ enriched medium, and incubated for $2 \mathrm{~d}$. The cells were centrifuged for $5 \mathrm{~min}$ at $150 \mathrm{~g}$, suspended in RPMI-1640 medium with dialyzed FCS. Here, only cybrid cells could grow. 2 wk later subcloning was performed by limiting dilution.
DNA fragmentation assay. DNA fragmentation was assayed by the modified method as described elsewhere (34). In brief, ML-1a cells were prelabeled with $\left[{ }^{3} \mathrm{H}\right] \mathrm{TdR}$ by incubating $2 \times 10^{5}$ cells $/ \mathrm{ml}$ in essential medium with $0.5 \mu \mathrm{Ci} / \mathrm{ml}\left[{ }^{3} \mathrm{H}\right] \mathrm{TdR}$ at $37^{\circ} \mathrm{C}$ for $4-16 \mathrm{~h}$. The cells were washed three times and resuspended in RPMI-1640 medium and plated in 96-well plates $\left(4 \times 10^{4}\right.$ cells/well, total volume 200 $\mu \mathrm{l})$ with or without the test samples; $1 \mu \mathrm{g} / \mathrm{ml}$ of cycloheximide was added to increase the sensitivity to TNF (35) but not to other apoptosis-inducing reagents. After incubation for $90 \mathrm{~min}$ or the indicated time, they were lysed by the addition of $50 \mu$ l of detergent buffer (10 $\mathrm{mM}$ Tris- $\mathrm{HCl} \mathrm{pH} 8.0$ containing 5 mM EDTA and $2.5 \%$ Triton $\mathrm{X}-100$ ) and incubated an additional $15 \mathrm{~min}$ at $4^{\circ} \mathrm{C}$. High-speed centrifugation was performed in an Eppendorf microcentrifuge at 12,000 $\mathrm{g}$ for $1 \mathrm{~min}$. The radioactivity in the supernatant represents DNA release into cells due to DNA fragmentation. For the total count, the cells were lysed by the addition of $20 \mu \mathrm{l}$ of $20 \%$ sodium dodecyl sulfate. The percent DNA release was calculated as follows:

\section{Percent DNA fragmentation $=$}

(cpm in test sample supernatant/total cpm) $\times 100$.

All results were determined in triplicate and expressed as mean \pm standard error.

Proliferation assay. Proliferation activity was estimated by $\left[{ }^{3} \mathrm{H}\right]$ TdR incorporation into ML-1a cells. Cells $\left(5 \times 10^{3} /\right.$ well $)$ were incubated with TNF for $72 \mathrm{~h}$. During the last $6 \mathrm{~h}\left[{ }^{3} \mathrm{H}\right] \mathrm{TdR}$ was added to each well $(0.5 \mu \mathrm{Ci} /$ well $)$. The cell suspension was harvested with the aid of a Filtermate 196 (Packard Instrument Co. Ltd., Meriden, CT) and the radioactivity bound to the filter measured by a Matrix 9600 (Packard Instrument Co. Ltd.). Inhibition of proliferative activity was calculated as follows:

\section{Percent inhibition $=$}

$\left[1-\left(\left[{ }^{3} H\right]\right.\right.$ TdR in test sample $) /\left(\left[{ }^{3} H\right]\right.$ TdR in control sample $\left.)\right] \times 100$.

All results were determined in triplicate and expressed as mean \pm standard error.

Differentiation assay. Differentiation-inducing activity was assayed colorimetrically by the modified method of Baechner and Nathan (36). In brief, $4 \times 10^{4}$ cells were plated in 96-well plates in the presence of test samples at a final volume of $200 \mu \mathrm{l}$ and incubated for $3 \mathrm{~d}$. Then $20 \mu \mathrm{l}$ of PBS containing $1.1 \mathrm{mg} / \mathrm{ml}$ of nitroblue tetrazolium and $1.1 \mu \mathrm{M}$ phorbol myristic acetate was added, and the solution was incubated another $2 \mathrm{~h}$. The reaction was then terminated by adding $50 \mu \mathrm{l} 2 \mathrm{~N} \mathrm{HCl}$ and cooling on ice for $30 \mathrm{~min}$. The medium was discarded, the formazan deposits were dissolved by adding $0.1 \mathrm{ml}$ dimethyl sulfoxide, and the dissolved formazan was measured at 590 $\mathrm{nm}$ by a spectrophotometer. The results were calculated and expressed as absorbance at 590/106 cells. All results were determined in triplicate and expressed as mean \pm standard error.

Respiration measurement. Oxygen consumption was measured with a Clark oxygen electrode (5300; Yellow Spring Instrument Co. Yellow Spring, $\mathrm{OH})$ as described (37). First, $0.6 \mathrm{ml}$ of cells $\left(4 \times 10^{7}\right.$ cells $/ \mathrm{ml})$ suspended in respiration medium $(0.25 \mathrm{M}$ sucrose, $20 \mathrm{mM}$ Hepes, pH 7.2, $2 \mathrm{mM} \mathrm{KH} \mathrm{KO}_{4}$ and $1 \mathrm{mM}$ EGTA) was injected into the respiration chamber $\left(37^{\circ} \mathrm{C}\right)$ and permeabilized with $0.025 \%$ digitonin. $1 \mathrm{mM}$ ADP and succinate were then added to give a final concentration of $5 \mathrm{mM}$ to initiate State 3 respiration. Oxygen consumption was calculated as the rate of change in the $\mathrm{O}_{2}$ concentration after the addition of a substrate, assuming an initial $\mathrm{O}_{2}$ concentration of $217 \mu \mathrm{M}$.

Assay for CPP32 protease. CPP32 protease activity was measured with a modified methods by Enari et al. (38). In brief, after cells $\left(1 \times 10^{6}\right)$ were incubated with test samples, cytosolic extracts were prepared by repeated freezing and thawing in $300 \mu \mathrm{l}$ extraction buffer (12.5 mM Tris, pH 7.0, 1 mM DTT, 0.125 mM EDTA, 5\% Glycerol, 1 $\mathrm{mM}$ PMSF, $1 \mu \mathrm{g} / \mathrm{ml}$ leupeptin, $1 \mu \mathrm{g} / \mathrm{ml}$ pepstatin, and $1 \mu \mathrm{g} / \mathrm{ml}$ aprotinin). Cell lysate was diluted with the buffer (50 mM Tris, $\mathrm{pH} 7.0,1$ $\mathrm{mM}$ DTT, $0.5 \mathrm{mM}$ EDTA, 20\% Glycerol) and incubated at $37^{\circ} \mathrm{C}$ in 
the presence of $20 \mu \mathrm{M}$ acetyl-Asp-Glu-Val-Asp-aminomethylcoumarin, CPP32 substrate. Fluorescent aminomethylcoumarin product formation was measured at excitation $360 \mathrm{nM}$, emission $460 \mathrm{nM}$ using Fluoroscan II (Labsystems, Helsinki, Finland).

\section{Results}

Depletion of the mitochondrial respiration chain abrogated TNF-induced apoptosis. Subclones of human myelogenous leukemia ML-1a cells that were deficient in functional MRC were isolated as described previously, (32) by selecting in enriched medium in the presence of $0.2 \mu \mathrm{g} / \mathrm{ml}$ of ethidium bromide for $8 \mathrm{wk}$. Ethidium bromide at this concentration inhibits mitochondrial DNA synthesis but not host DNA synthesis, reduces mitochondrial DNA derived mitochondrial protein, and thus reduces mitochondrial respiratory functions. Several clones were isolated from ethidium bromide-resistant cells by limiting dilution. Five clones, clones 2, 5, 11, 19, and 20, grew well in enriched medium but could not survive in essential medium. They required a source of exogenous pyrimidine, presumably because of the absence of a functional MRC (32). To examine electron transfer in the state 3 respiration in these cells, succinate was used as a substrate to measure the electron flow through complex II-complex III-complex IV (Fig. 1). Oxygen consumption was not detectable in clone 19 and was significantly reduced in clones $2,5,11$, and 20 (5\% of parental cell) (Table I).

The effect of TNF on the induction of apoptosis in ML-1a and clones 2, 5, 11, 19, and 20 was investigated next. As shown in Table I, most of the ML-1a cells underwent apoptosis within $90 \mathrm{~min}$. In contrast, we could detect only a slight induction of apoptosis by TNF in clones $2,5,11$, and 20 and no significant induction in clone 19 (Table I and Fig. 2 A). Furthermore, we could not observe any apoptosis in clone 19 even after $8 \mathrm{~h}$ of TNF treatment (data not shown). Since specific binding of TNF to these clones was similar to that of ML-1a cells (data

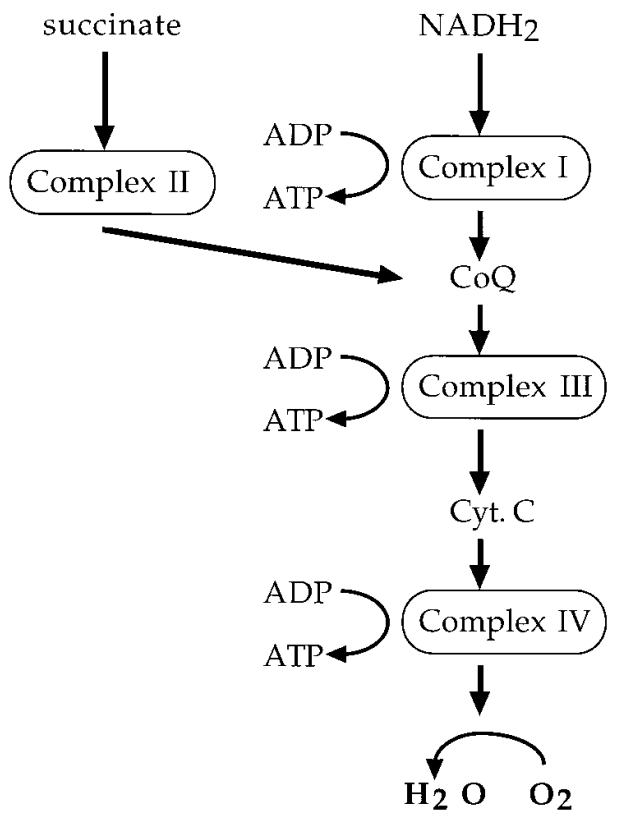

Figure 1. Electron flow in mitochondrial respiratory chain. Succinate is a substrate. $\mathrm{CoQ}$, coenzyme $\mathrm{Q}$; cyt. C, cytochrome $\mathrm{C}$. not shown), downregulation of TNF receptor was not the cause of the inhibition.

We have shown previously that TNF can also induce differentiation and inhibit proliferation in ML-1a cells (39). Interestingly, in clone 19 and 20, TNF exhibited differentiation-inducing activity (Fig. $2 \mathrm{~B}$ ) and growth inhibitory activity (Fig. $2 \mathrm{C}$ ) even though it had no or very low apoptosis-inducing activity (Fig. 2 A). These results indicate that TNF-induced apoptosis signaling was specifically blocked in these cells, presumably due to the absence of a functional MRC. Furthermore, it suggests that normal mitochondrial function is not required for TNF-induced differentiation and inhibition of proliferation.

To examine whether the ethidium bromide treatment solely affected mitochondrial function, mitochondria were reintroduced into clones 19 and 20. The cybrids were tested for recovery of apoptotic response. Clones 19 and 20 were fused with platelets derived from a healthy donor and incubated in essential medium for $3 \mathrm{wk}$. In essential medium, only reconstituted cybrid cells could grow, but not clones 19 and 20, nor platelets. Subclones were isolated by limiting dilution. All the cybrid clones tested have recovered mitochondrial respiration and TNF-induced apoptosis (Table I). Thus, intact mitochondrial respiratory function is essential for TNF-induced apoptosis.

Involvement of mitochondria in serum depletion- and antiFas-induced apoptosis, but not staurosporine, H-7-, and okadaic acid-induced apoptosis. Next, we examined whether mitochondrial respiration was required for apoptosis induced by other reagents. First, the effect of anti-Fas antibody was examined. Anti-Fas antibody induced apoptosis in parental ML-1a cells, but not in clone 19 cells; however, the apoptotic response reappeared in the cybrid clones (Fig. $3 A$ ). Serum starvation for $48 \mathrm{~h}$ also induced apoptosis in ML-1a cells (Fig. $3 \mathrm{~B}$ ), but not in clone 19 cells; again, the apoptotic response reappeared

Table I. Oxygen Consumption and the Effect of TNF in Inducing DNA Fragmentation in ML-1a, Ethidium Bromide-resistant Clones, and their Cybrids

\begin{tabular}{lcrr}
\hline & & \multicolumn{2}{c}{ DNA fragmentation $(\%)$} \\
\cline { 3 - 4 } Cells & Respiration & Control & $+\mathrm{TNF}$ \\
\hline & $\left(n\right.$ M/min per $10^{7}$ cells $)$ & & \\
ML-1a & 6.7 & $7.3 \pm 0.2$ & $84.1 \pm 1.7$ \\
2 & 0.35 & $6.1 \pm 0.5$ & $13.4 \pm 0.5$ \\
5 & 0.95 & $11.0 \pm 0.2$ & $21.5 \pm 0.5$ \\
11 & 0.3 & $6.3 \pm 0.1$ & $16.0 \pm 0.4$ \\
19 & $<0.07$ & $3.9 \pm 0.1$ & $4.1 \pm 0.1$ \\
20 & 0.32 & $4.5 \pm 0.3$ & $14.3 \pm 0.5$ \\
$19-1$ & 11.0 & $11.5 \pm 0.9$ & $75.3 \pm 1.3$ \\
$19-2$ & 4.0 & $20.5 \pm 2.1$ & $80.2 \pm 0.7$ \\
$19-6$ & 4.5 & $16.6 \pm 0.5$ & $66.1 \pm 0.3$ \\
$20-1$ & 13.5 & $20.5 \pm 2.1$ & $88.9 \pm 2.9$ \\
$20-2$ & 4.8 & $12.9 \pm 0.4$ & $62.3 \pm 6.1$ \\
& & &
\end{tabular}

Oxygen consumption of each clone was detected in the presence of succinate as substrate as described in Methods. DNA fragmentation was detected after 90-min incubation of each clone in the presence of $1 \mu \mathrm{g} /$ $\mathrm{ml}$ of cycloheximide with or without $1 \mathrm{nM}$ TNF as described in Methods. All results of DNA fragmentation were determined in triplicate and expressed as mean \pm standard error. 

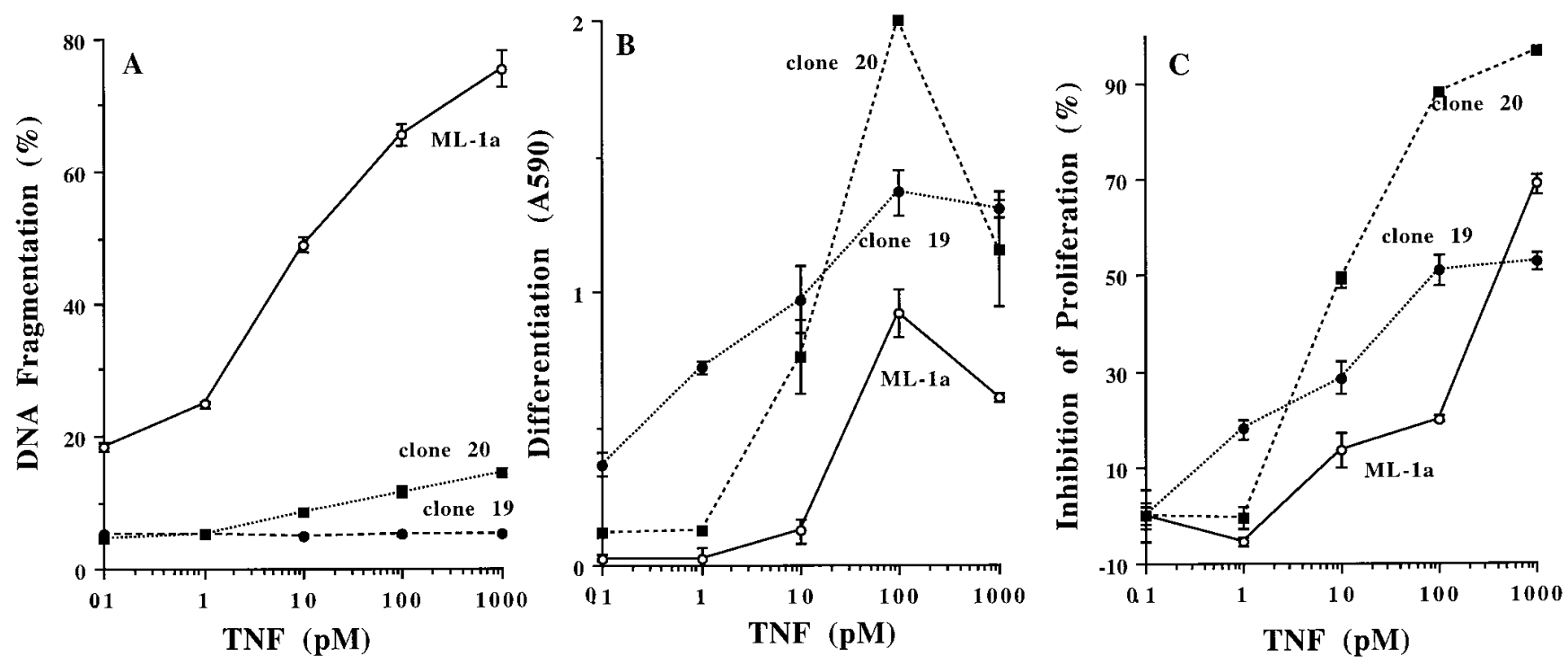

Figure 2. Induction of DNA fragmentation, differentiation, and inhibition of proliferation by TNF in ML-1a, clone 19, and clone 20. (A) $\left[{ }^{3} \mathrm{H}\right] \mathrm{TdR}$ prelabeled cells incubated with the indicated concentration of TNF and $1 \mu \mathrm{g} / \mathrm{ml}$ cycloheximide for 90 min were tested for DNA fragmentation as described in Methods. $(B)$ cells incubated with indicated amount of TNF for $3 \mathrm{~d}$ were tested for differentiation inducing activity as described in Methods. $(C)$ Cells incubated with indicated concentration of TNF for $3 \mathrm{~d}$ were tested for inhibition of proliferation as described in Methods.

in the cybrid clones. In contrast, staurosporine, a protein kinase $\mathrm{C}(\mathrm{PKC})$ inhibitor, induced apoptosis even in respiration deficient clone 19 (Fig. 4 A). H-7, another PKC inhibitor, and okadaic acid, a protein phosphatase inhibitor, also induce apoptosis in ML-1a cells and in clone 19 (Fig. 4, $B$ and $C$ ). These results indicate that mitochondrial respiration is needed for the induction of apoptosis by anti-Fas and serum depletion but not by staurosporine, H-7, or okadaic acid.

Involvement of mitochondria in CPP32-like protease activation by TNF but not by staurosporine. CPP32 is now considered as one of the key mediators in apoptosis. However, their role in TNF-induced apoptosis is not completely clear. First, we tested whether CPP32-like protease is involved in TNF- and staurosporine-induced apoptosis. Z-DEVD- $\mathrm{CH}_{2} \mathrm{~F}$, an irreversible inhibitor of CPP32, inhibited TNF- and staurosporineinduced apoptosis in ML-1a (Fig. 5, $A$ and $B$, respectively) and staurosporine-induced apoptosis in clone 19 (Fig. $5 C$ ), indicating that CPP32-like protease activation is involved in both apoptosis. We then tested the effect of TNF and staurosporine on the activation of CPP32-like protease by fluorogeneic assay in ML-1a cells, in respiration deficient clone 19, and in reconstituted clones. As shown in Table II, TNF-induced activation of CPP32-like protease was observed in ML-1a, not in clone 19, but reappeared in reconstituted clones. Staurosporine increased CPP32-like protease activity up to twelve times in ML$1 \mathrm{a}, 10$ times in clone 19 , and $\sim 10$ times in reconstituted clones.

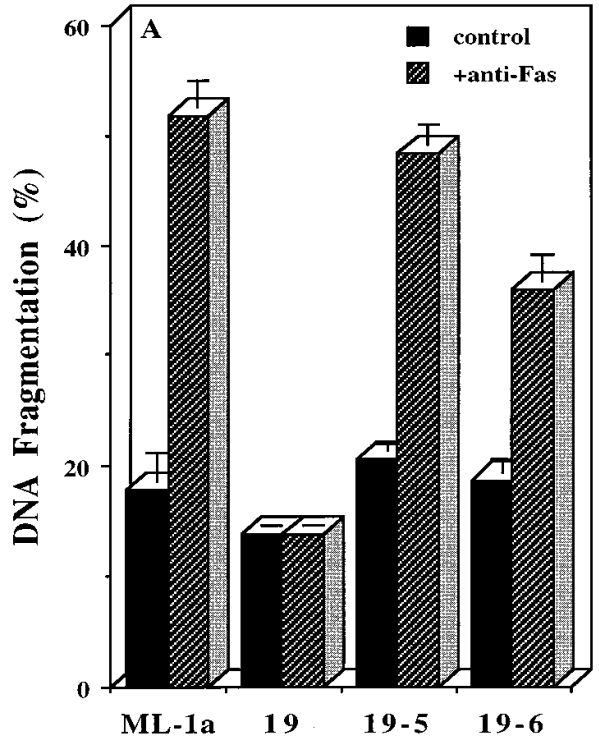

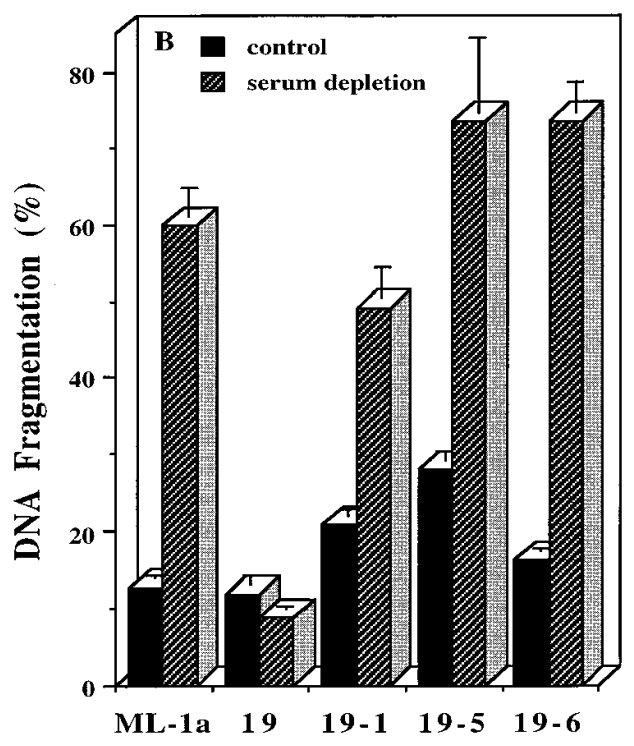

Figure 3. Induction of apoptosis by anti-Fas, serum starvation, in ML-1a, clone 19 and cybrid clones. $\left[{ }^{3} \mathrm{H}\right] \mathrm{TdR}$ prelabeled ML-1a, clone 19, and cybrid clones were incubated in RPMI-1640 medium with or without $2 \mu \mathrm{g} / \mathrm{ml}$ anti-Fas antibody for $24 \mathrm{~h}(A)$, with or without $10 \% \mathrm{FCS}$ for $48 \mathrm{~h}(B)$ and tested for DNA fragmentation as described in Methods. 

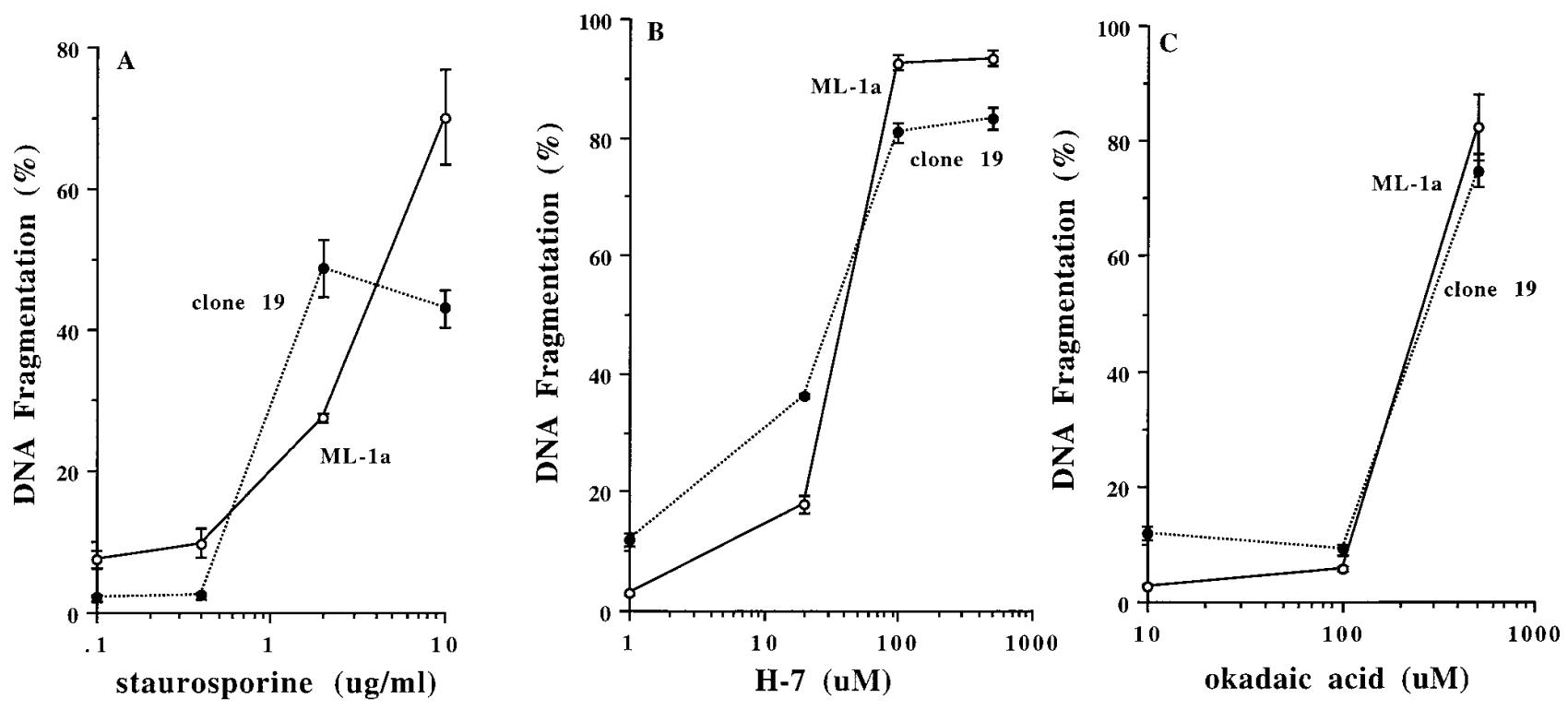

Figure 4. Induction of apoptosis by staurosporine, H-7, and okadaic acid in ML-1a, clone 19. $\left[{ }^{3} \mathrm{H}\right] \mathrm{TdR}$ prelabeled ML-1a and clone 19 were incubated in RPMI-1640 medium plus 10\% FCS with indicated concentration of staurosporine $(A)$, H-7 $(B)$, and okadaic acid $(C)$ for 6 h, and tested for DNA fragmentation as described in Methods.

These results indicate that mitochondrial respiratory function is necessary for CPP32-like protease activation in TNF- but not in staurosporine-induced apoptosis.

\section{Discussion}

In this report, we investigated the role of mitochondrial respiration in apoptosis signaling. To study the direct involvement of mitochondria in TNF-induced apoptosis, we obtained five clones that had deficiencies in mitochondrial respiration by treating the cells with ethidium bromide, and several reconstituted clones derived from respiration-deficient cells fused with platelets. We did not observe any evidence of TNF-induced apoptosis in the respiration-free clone 19. However, there was a slight but significant TNF-induced apoptosis in the other four clones, in which low oxygen consumption could be detected.
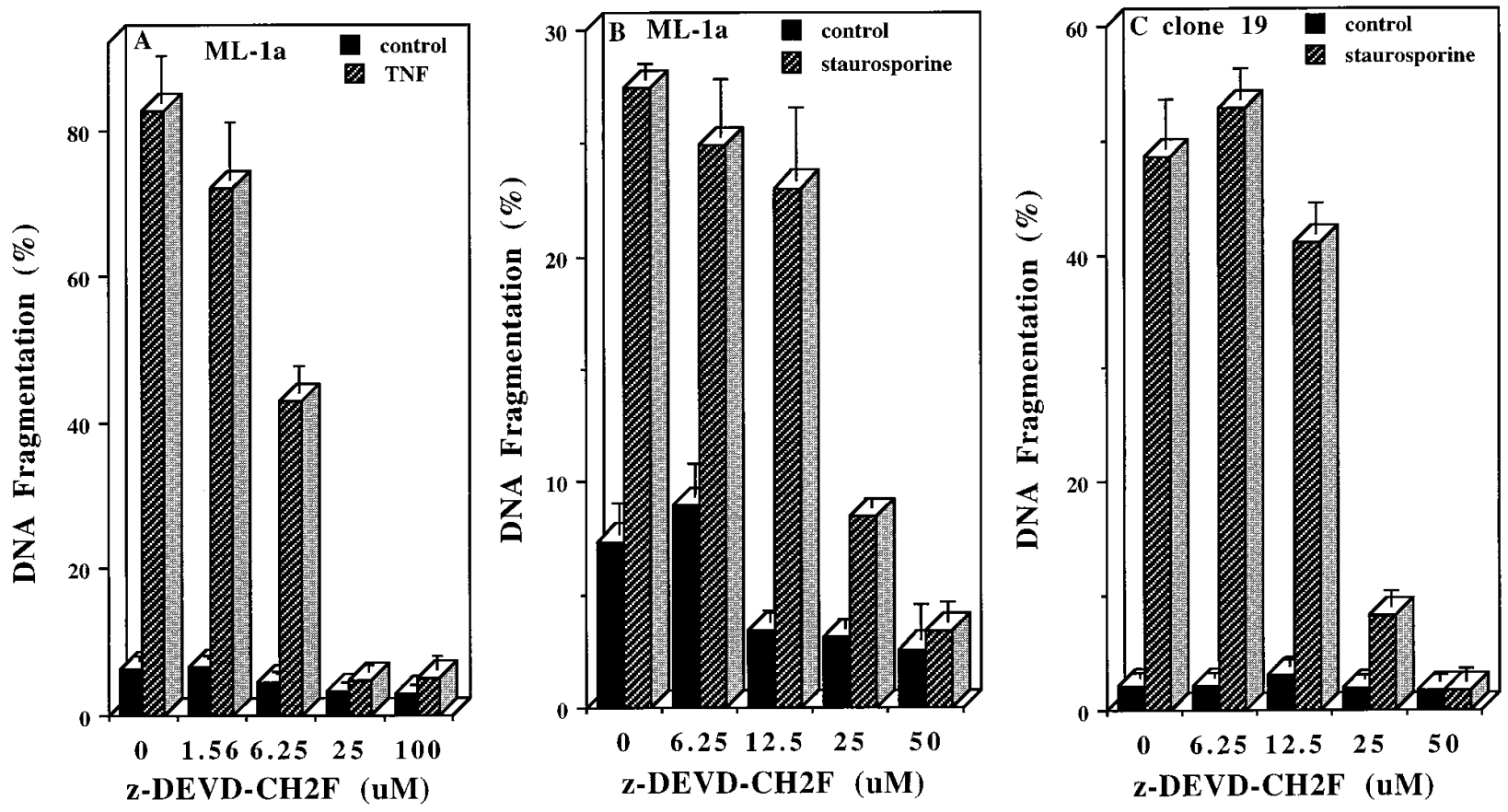

Figure 5. Inhibition of TNF- and staurosporine-induced apoptosis by z-DEVD- $\mathrm{CH}_{2} \mathrm{~F}$. $(A)\left[{ }^{3} \mathrm{H}\right] \mathrm{TdR}$ prelabeled ML-1a $(A$ and $B)$ or clone $19(B)$ were incubated with indicated amount of z-DEVD- $\mathrm{CH}_{2} \mathrm{~F}$ in the absence or presence of $1 \mathrm{nM}$ TNF and $1 \mu \mathrm{g} / \mathrm{ml}$ cycloheximide for $90 \mathrm{~min}(A)$ or $2 \mu \mathrm{g} / \mathrm{ml}$ staurosporine for $6 \mathrm{~h}(B$ and $C$ ) and tested for DNA fragmentation as described in Methods. 
Although the treatment with ethidium bromide at low concentration is known to inhibit mitochondrial DNA synthesis and decrease intact mitochondrial DNA (40), the precise molecular defect(s) in our respiration deficient cells are not known. Nevertheless it is clear that mitochondria DNA-derived proteins in MRC are affected to various degree in different clones. Clone 19 appears to be most affected. Thus profound depletion of mitochondrial respiration might be required to abrogate respiration and TNF-induced apoptotic response. Since reintroduction of mitochondria to clones 19 and 20 restored oxygen consumption and the apoptotic response, we concluded that mitochondrial respiration is critically involved in TNF-induced apoptosis.

TNF can induce necrosis $(30,31)$ in L929, a mouse fibroblast cell line widely used as a target for TNF analysis. In this system, the role of ROS from mitochondria in cell death has been reported (2-5). Contradictory results have been reported on the role of mitochondria in TNF-induced necrosis in L929 cells by using cells that had deficiencies in mitochondria (5, 41). One group showed that a decrease in mitochondrial function resulted in a decrease in TNF-induced cytotoxicity. Another group showed that treatment of cells with chloramphenicol can induce cells to have a 50-80\% deficiency in mitochondrial DNA-encoded respiratory enzyme, but complete sensitivity to TNF-induced cytotoxicity. There were major differences between their experimental conditions that may explain their discrepant results. The former used established clones after ethidium bromide and chloramphenicol treatment and the latter used cells treated with chloramphenicol for $3 \mathrm{wk}$. Cells obtained by the former group might have had less mitochondrial respiration than those used by the latter group. The remaining mitochondrial function per cell may be very critical. If the number of functional mitochondria decreases, electron transport per mitochondria might increase to compensate for the decrease in ATP, and the generation of ROS, which is one of the possible mediators in apoptosis and necrosis (22), per mitochondria might increase. Therefore, the number of active mitochondria per cell might be important in TNF-induced necrosis.

Jacobson et al. have reported that simian virus $40 \mathrm{~T}$-antigen transformed human fibroblast cell ( $\rho_{0}$ cells) with deficiencies in mitochondria underwent apoptosis after serum (42) and oxy-

Table II. Activation of CPP-32-like Protease by TNF and Staurosporine in ML-1a, Respiration-deficient Clone 19, and Reconstituted Clones

\begin{tabular}{lrrrr}
\hline & \multicolumn{3}{c}{ CPP-32-like activity (FIU/min mg protein) } \\
\cline { 2 - 5 } Cells & \multicolumn{2}{c}{ Control + TNF } & \multicolumn{2}{c}{ Control + staurosporine } \\
\hline ML-1a & $0.60 \pm 0.01$ & $10.47 \pm 0.87$ & $0.91 \pm 0.04$ & $11.40 \pm 0.56$ \\
19 & $1.28 \pm 0.04$ & $1.23 \pm 0.04$ & $0.59 \pm 0.04$ & $6.15 \pm 0.27$ \\
$19-1$ & $1.62 \pm 0.05$ & $13.00 \pm 0.05$ & $1.40 \pm 0.05$ & $13.92 \pm 0.21$ \\
$19-5$ & $1.46 \pm 0.03$ & $12.82 \pm 0.08$ & $1.37 \pm 0.02$ & $13.77 \pm 0.56$ \\
$19-6$ & $1.15 \pm 0.06$ & $11.58 \pm 0.17$ & $1.56 \pm 0.09$ & $15.14 \pm 0.52$
\end{tabular}

$1 \times 10^{6}$ cells were treated with $1 \mu \mathrm{g} / \mathrm{ml}$ cycloheximide and $1 \mathrm{nM}$ TNF $(T N F)$ or $5 \mu \mathrm{g} / \mathrm{ml}$ of staurosporine for $90 \mathrm{~min}$ or $6 \mathrm{~h}$, respectively, at $37^{\circ} \mathrm{C}$. CPP-32-like protease activity in each clone was assayed as described in Methods. gen deprivation (43). Their $\rho_{0}$ cells behave like clone 20, which is deficient, but not completely free of oxygen consumption. Clone 20 still can undergo TNF-induced apoptosis in a slower kinetics (Table I), and apoptosis by serum deprivation (data not shown). On the other hand, clone 19 shows no detectable oxygen consumption and does not undergo apoptosis by serum starvation. The best explanation for these differences hinges on the difference in baseline oxygen consumption in the $\rho_{0}$ cells, clone 20 , and clone $19 . \rho_{0}$ cell and clone 20 consumes 0.1 and $0.021 \mathrm{fM} \mathrm{O}_{2}$ per cell per min respectively whereas clone 19 consumes $<0.007 \mathrm{fM} \mathrm{O}_{2}$ per cell per min $(<7 \%$ of rho cell levels). Thus, there may be a critical threshold below which apoptosis induction will be severely affected.

Besides apoptosis, TNF induces differentiation and inhibits proliferation in ML-1a cells (39). Present results indicate an involvement of mitochondrial function in TNF-induced apoptosis, but not in TNF-induced differentiation or inhibition of proliferation. These observations are consistent with our previous observation that TPCK, a specific inhibitor of chymotrypsintype protease, blocked TNF-induced apoptosis, but not differentiation nor growth inhibition (44).

In the present study, we showed that the mitochondrial respiration is necessary for the induction of apoptosis by physiological stimulants such as TNF, anti-Fas, and serum starvation, but not by non-physiological stimulants such as staurosporine, $\mathrm{H}-7$, and okadaic acid. These results suggest that nonphysiological stimulant might bypass the requirement of mitochondrial respiration to induce apoptosis. The dose response of $\mathrm{H}-7$ and okadaic acid used to induce apoptosis in ML-1a and in respiration-deficient clone is similar. However, we observed inhibitory action in clone 19 by staurosporine in higher concentration. Thus additional inhibitory mechanisms might be induced by staurosporine in respiration deficient clones. Further analysis will be needed to identify the difference in apoptotic signaling of staurosporine versus $\mathrm{H}-7$ and okadaic acid.

CPP32, a cysteine protease, has been shown to play a critical role in Fas-mediated (17), spontaneous (16), and staurosporine-mediated (18) apoptosis. In this report, we showed that a CPP32-like protease is also involved in TNF-induced apoptosis by the use of CPP32 inhibitor. We showed TNFinduced CPP32-like protease activation by fluorogeneic assay, and we could also detect the activation of CPP32 itself by Western blotting (data not shown). However, we do not know whether the induction of apoptosis is due to CPP32 itself or CPP32-like protease with similar substrate specificity. The report by Chinnaiyan et al. (45) supports the idea that CPP32-like but not CPP32 itself might also be involved in apoptosis. Most importantly, TNF could not activate CPP32-like protease in respiration deficient clones. Thus, mitochondrial function is required at a step before CPP32-like protease activation in TNFinduced apoptosis signaling.

The mechanism whereby functional mitochondria affect the activation of CPP32-like protease is not clear at this point. Several investigators have shown that apoptosis-inducing molecules such as cytochrome $c$ are released from mitochondria after apoptosis induction $(29,46)$. It has also been shown that the release of these molecules from mitochondria is the key event for CPP32-like protease activation. We have reported that TNF-induced necrosis and the damage to the mitochondria in L.P3 cells, a clone of L929, was mediated through the generation of ROS from MRC (4). We have also detected TNF-induced ROS generation from MRC in ML-1a cells but 
not in respiration deficient clones (data not shown). Thus, generation of ROS from functional MRC might cause mitochondrial damage to release apoptosis-inducing molecules leading to CPP32 activation. It is also possible that ROS may directly affect an upstream protease to activate CPP32-like protease. An alternative hypothesis in which ROS is minimally involved might also be envisioned. One possibility is that mitochondrial activity may directly or indirectly regulate gene expression leading to a change in the relative expression of pro-life vs prodeath proteins. Another possibility is that mitochondria might regulate cellular metabolism that is essential in TNF-induced apoptosis. In this hypothesis, loss of functional mitochondria might change the cytosolic milieu which are necessary for TNF-induced apoptosis.

The reason why protein kinase and phosphatase inhibitors can bypass the mitochondrial respiration requirement is not clear. Staurosporine may directly or indirectly damage mitochondria to release apoptosis-inducing factors. Alternatively, staurosporine may directly activate a cytosolic factor which is required for the activation of the protease cascade. Experiments are now underway to elucidate the precise mechanisms that link mitochondrial function to CPP32-like protease activation.

\section{Acknowledgments}

Authors are thankful to Dr. Gordon Mills for his support and helpful suggestions and Rita Proske for her technical help. We thank Dr. Hans Müller-Eberhard for his helpful suggestions and Walter Pagel for his editorial reviews of the manuscript.

\section{References}

1. Carswell, E.A., L.J. Old, R.L. Kassel, S. Green, N. Fiore, and B. Williamson. 1975. An endotoxin-induced serum factor that causes necrosis of tumors. Proc. Natl. Acad. Sci. USA. 72:3666-3670.

2. Matthews, N. 1983. Anti-tumor cytotoxin produced by human monocytes: studies on its mode of action. Br. J. Cancer. 48:405-410.

3. Schulze-Osthof, K., A.C. Bakker, B. Vanhaesebroeck, R. Beyaert, W.A. Jacob, and W. Fiers. 1992. Cytotoxic activity of tumor necrosis factor is mediated by early damage of mitochondrial functions. J. Biol. Chem. 267:5317-5323.

4. Higuchi, M., K. Shirotani, N. Higashi, S. Toyoshima, and T. Osawa. 1992. Damage to mitochondrial respiration chain is related to phospholipase $\mathrm{A}_{2}$ activation caused by tumor necrosis factor. J. Immunother. 2:41-49.

5. Schulze-Osthoff, K., R. Beyaert, V. Vandevoorde, G. Haegeman, and W. Fiers. 1993. Depletion of mitochondrial electron transport abrogates the cytotoxic and gene-inductive effects of TNF. EMBO (Eur. Mol. Biol. Organ.) J. 12: 3095-3104.

6. Kobayashi, Y., J. Sawada, and T. Osawa. 1979. Activation of membrane phospholipase A by guinea pig lymphotoxin (GLT). J. Immunol. 122:791-794.

7. Neale, M.L., R.A. Fiera, and D. Matthews. 1988. Involvement of phospholipase A2 activation in tumor cell killing by tumor necrosis factor. Immunology. 64:81-85.

8. Hayakawa, M., N. Ishida, K. Takeuchi, S. Shibamoto, T. Hori, N. Oku, F. Ito, and M. Tsujimoto. 1993. Arachidonic acid-selective cytosolic phospholipase A2 is crucial in the cytotoxic action of tumor necrosis factor. J. Biol. Chem. 268: $11290-11295$.

9. Obeid, L.M., C.M. Linardic, L.A. Karolak, and Y.A. Hannun. 1993. Programmed cell death induced by ceramide. Science (Wash. DC). 259:1769-1772.

10. Kolesnick, R., and D.W. Golde. 1994. The sphingomyelin pathway in tumor necrosis factor and interleukin-1 signaling. Cell. 77:325-340.

11. Takeda, Y., S. Shimada, M. Sugimoto, H.J. Woo, M. Higuchi, and T. Osawa. 1985. Purification and characterization of a cytotoxic factor produced by a mouse macrophage hybridoma. Cell. Immunol. 96:277-283.

12. Ruggiero, V., S.E. Johnson, and C. Baglion. 1987. Protection from tumor necrosis factor cytotoxicity by protease inhibitors. Cell. Immunol. 107:317325 .

13. Suffys, P., R. Beyaert, F. Van Roy, and W. Fiers. 1988. Involvement of a serine protease in tumor-necrosis-factor-mediated cytotoxicity. FEBS Lett. 178: 257-265

14. Miura, M., R.M. Friedlander, and J. Yuan. 1995. Tumor necrosis factorinduced apoptosis is mediated by CrmA-sensitive cell death pathway. Proc. Natl. Acad. Sci. USA. 92:8318-8322.
15. Williams, M.S., and P.A. Henkart. 1994. Apoptotic cell death induced by intracellular proteolysis. J. Immunol. 153:4247-4255.

16. Nicholson, D.W., A. Ali, N.A. Thornberry, J.P. Vailancourt, C.K. Ding, M. Gallant, Y. Gereau, P.R. Griffin, M. Labelle, Y.A. Lazebnik, et al. 1995. Identification and inhibition of the ICE/CED-3 protease necessary for mammalian apoptosis. Nature (Lond.). 376:37-43.

17. Schlegel, J., I. Peters, S. Orrenius, D.K. Miller, N.A. Thornberry, T.-T. Yamin, and D.W. Nicholson. 1996. CPP32/Apopain is a key interleukin 1b converting enzyme-like protease involved in Fas-mediated apoptosis. J. Biol. Chem. 271:1841-1844.

18. Jacobson, M.D., M. Weil, and M.C. Raff. 1996. Role of Ced-3/ICE-family proteases in staurosporine-induced programmed cell death. J. Cell Biol. 133 : 1041-1051.

19. Fujita, E., T. Mukasa, T. Tsukahara, K. Arahata, S. Omura, and T. Momoi. 1996. Enhancement of CPP32-like activity in the TNF-treated U937 cells by the proteasome inhibitors. Biochem. Biophys. Res. Commun. 224:74-79.

20. Mizuo, M., A.M. Chinnaiyan, F.C. Kischkel, K. O'Rourke, A. Shevchenko, J. Ni, C. Scaffidi, J.D. Bretz, M. Zhang, R. Gentz, et al. 1996. FLICE, a novel FADD-homologous ICE/CED-3-like protease, is required to CD95 (Fas/APO-1) death-inducing signaling complex. Cell. 85:817-827.

21. Boldin, M.P., T.M. Goncharov, Y.V. Goltsev, and D. Wallach. 1996. Involvement of MACH, a novel MORT1/FADD-interacting protease, in Fas/ APO-1 and TNF receptor-induced cell death. Cell. 85:803-815.

22. Lennon, S.V., S.J. Martin, and T.G. Cotter. 1991. Dose-dependent induction of apoptosis in human tumor cell lines by widely diverging stimuli. Cell Prolif. 24:203-214.

23. Wong, G.H.W., J.H. Elwell, L.W. Oberly, and D.V. Goeddel. 1989 Manganous superoxide dismutase is essential for cellular resistance to cytotoxicity of tumor necrosis factor. Cell. 58:923-931.

24. Hennet, T., C. Richte, and E. Peterhans. 1992. Tumor necrosis factor- $\alpha$ induced superoxide anion generation in mitochondria of L929 cells. Biochem. J. 289:587-592.

25. Goossens, V., J. Grooten, K.D. Vos, and W. Fiers. 1995. Direct evidence for tumor necrosis factor-induced mitochondrial reactive oxygen intermediates and their involvement in cytotoxicity. Proc. Natl. Acad. Sci. USA. 92:8115-8119.

26. Richter, C. 1993. Pro-oxidant and mitochondrial $\mathrm{Ca}^{2+}$ : their relationship to apoptosis and oncogenesis. FEBS Lett. 325:104-107.

27. Zamzami, N., A.S. Susin, P. Merchetti, T. Hirsch, I. Gómez-Monterrey, M. Castedo, and G. Kromer. 1996 Mitochondrial control of nuclear apoptosis. J. Exp. Med. 183:1533-1544.

28. Hennet, T., G. Bertoni, C. Richter, and E. Peterhans. 1993. Expression of Bcl-2 protein enhances the survival of mouse fibrosarcoid cells in tumor necrosis factor-mediated cytotoxicity. Cancer Res. 53:1456-1460.

29. Liu, X., C.N. Kim, J. Yang, R. Jemmerson, and X. Wang. 1996. Induction of apoptotic program in cell-free extracts: requirement of dATP and cytochrome c. Cell. 86:147-157.

30. Vanhaesebroeck, B., S.V. Bladel, A. Lenaerts, P. Suffys, R. Beyaert, R. Lucas, F.V. Roy, and W. Fiers. 1991. Two discrete types of tumor necrosis factor-resistant cells derived from the small cell line. Cancer Res. 51:2369-2477.

31. Schulze-Osthoff, K., P.H. Krammer, and W. Droge. 1994. Divergent signalling via APO-1/Fas and TNF receptor, two homologous molecules involved in physiological cell death. EMBO (Eur. Mol. Biol. Organ.) J. 13:4587-4596.

32. King, M.P., and G. Attardi. 1989. Human cells lacking mtDNA: replication with exogenous mitochondria by complementation. Nature (Lond.). 246: 500-503.

33. Chomyn, A., S.T. Lai, R. Shakeley, N. Bresolin, G. Scarlato, and G. Attardi. 1994. Platelet-mediated transformation of mtDNA-less human cells: analysis of phenotypic variability among clones from normal individuals and complementation behavior of the tRNA ${ }^{\mathrm{Lys}}$ mutation causing myoclonic epilepsy and ragged red fibers. Am. J. Hum. Genet. 54:966-974.

34. Higuchi, M., S. Singh, and B.B. Aggarwal. 1995. Characterization of the apoptotic effects of human tumor necrosis factor; development of highly rapid and specific bioassay for human tumor necrosis factor and lymphotoxin using human target cells. J. Immunol. Methods. 178:173-181.

35. Kull, F.C., and P. Cuatrecasas. 1981. Possible requirement of internalization in the mechanism of in vitro cytotoxicity in tumor necrosis serum. Cancer Res. 41:4885-4890.

36. Baehner, R.L., and D.G. Nathan. 1968. Quantitative nitroblue tetrazolium test in chronic granulomatous disease. N. Engl. J. Med. 278:971-976.

37. Granger, D.L., and A.L. Lehninger. 1982. Sites of inhibition of mitochondrial electron transport in macrophage-injured neoplastic cells. J. Cell Biol. 95:527-535.

38. Enari, M., R.V. Talanian, W.W. Wong, and S. Nagata. 1996. Sequential activation of ICE-like and CPP-32-like proteases during Fas-mediated apoptosis. Nature (Lond.). 380:723-726.

39. Higuchi, M., and B.B. Aggarwal. 1994. Differential role of the p60 and p80 forms of the TNF receptor in TNF induced cytotoxicity, DNA fragmentation and differentiation. J. Immunol. 152:4017-4025.

40. Desjardins, P., E. Frost, and R. Morais. 1985. Ethidium bromide-induced loss of mitochondrial DNA from primary chicken embryo fibroblasts. Mol. Cell. Biol. 5:1163-1169.

41. O'Donnell, V.B., S. Spycher, and A. Azzi. 1995. Involvement of oxi- 
dants and oxidant-generating enzyme(s) in tumor-necrosis-factor-a-mediated apoptosis: role for lipoxygenase pathway but not mitochondrial respiratory chain. Biochem. J. 310:133-141.

42. Jacobson, M.D., J.F. Burne, M.P. King, T. Miyashita, J.C. Reed, and M.C. Raff. 1993. Bcl-2 blocks apoptosis in cells lacking mitochondrial DNA. Nature (Lond.). 361:365-369.

43. Jacobson, M.D., and M.C. Raff. 1995. Programmed cell death and Bcl-2 protection in very low oxygen. Nature (Lond.). 374:814-816.

44. Higuchi, M., S. Singh, H. Chan, and B.B. Aggarwal. 1995. Protease in- hibitors differentially regulate tumor necrosis factor-induced apoptosis, nuclear factor- $\kappa$ B activation, cytotoxicity, and differentiation. Blood. 86:2248-2256.

45. Chinnaiyan, A.M., K. Orth, K. O'Rourke, H. Duan, G.G. Poirier, and V.M. Dixit. 1996. Molecular ordering of the cell death pathway. J. Biol. Chem. 271:4573-4576.

46. Zamzami, N., S.A. Susin, P. Marchetti, T. Hirsch, I. Gómez-Monterrey, M. Castedo, and G. Kroemer. 1996. Mitochondrial control of nuclear apoptosis. J. Exp. Med. 183:1533-1544. 